\title{
LOOKING TO LITERATURE FOR TRANSFORMATION
}

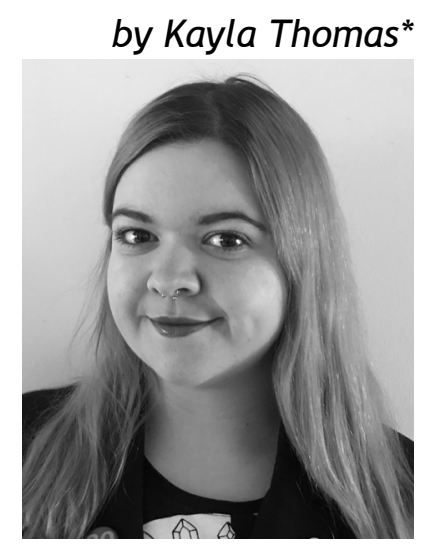

'And poetry perhaps is born again' - Shalom Freedman

\section{Introduction}

Law is a social discipline that concerns every aspect of the human experience. Legal education prepares law students for a career in this social discipline and should thus produce socially minded professionals that consider and value the vast spectrum of the human experience. ${ }^{1}$ In the post-1994 context of South African legal education, transformation of the legal syllabus is required to ensure a general jurisprudential approach to law that gives value and acknowledgment to the multitude of experiences, perspectives and voices that make up the human experience which is central to the law. This is to ensure substantive justice and an approach to law that values previously dismissed or devalued perspectives such as those of females, Africans and subjective and trans-disciplinary approaches to legal education. ${ }^{2}$

* Third year BA Law student majoring in English at the University of Pretoria. In this adaptation of a JUR 310 research essay, the role of diverse English literature as a part of a multidisciplinary post-1994 South African legal education is explored as central to creating morally and socially conscious legal professionals.

1 M Nussbaum 'Cultivating humanity in legal education' (2003) 70 The University of Chicago Law Review 270.

2 Y Waghid 'Knowledge Production and higher education transformation in South Africa: Towards reflexivity in university teaching, research and community service' (2002) 43 Higher Education 467. 
Law students at the University of Pretoria are required to take English literature courses as part of their legal education in specifically the LLB and BA Law programs. This contributes in part, to establishing a more inclusive jurisprudence and a legal education focussed on transformation. By including fields such as the humanities in the legal syllabus, assumed binaries of objective, legally relevant fields of knowledge versus subjective social sciences are blurred in favour of a non-dualistic approach to legal education. ${ }^{3}$ However, the limited inclusion of diverse perspectives - namely, African and female perspectives in African and female texts - stunts the transformative efforts of the Law Faculty, by exposing law students studying literature to predominantly Eurocentric and male texts. ${ }^{4}$

The English literature that is being taught to law students plays a role in shaping critical and ethically conscious lawyers, as well as in contributing to a transformative approach to legal education in post1994 South Africa by engaging with different perspectives. Value lies in engaging specifically with previously devalued perspectives in a substantive way. ${ }^{5}$ While limited progress has been made to include diverse and previously undervalued perspectives, a more inclusive English syllabus will produce more ethically conscious and humanistic law students and lawyers. ${ }^{6}$

Incorporating more literature of marginalised groups into the law syllabus in a non-hierarchical way will challenge and perhaps begin to dismantle the pre-democratic dominance of structural and psychological oppression, systems of patriarchy, and the black inferiority complex. ${ }^{7}$

\section{The role of English literature in legal education}

To evaluate the role of English literature in law and legal education, a discussion of general and restricted jurisprudence will be of value. Jurisprudence in this discussion being the critical evaluation of the interplay between legal consciousness and humanism with regard to educating moral legal professionals. Restricted jurisprudence is typically formalistic in nature and awards limited value or relevance

3 Nussbaum (n 1) 271. See also G Minda Postmodern legal movements: Law and jurisprudence at century's end (1995) 111.

4 University of Pretoria, Department of English ENG 110, 120, 210 and 220 study guides (2018).

$5 \quad$ Nussbaum (n 1) 271.

6 B Lindfors 'African literature teaching in South African University English Departments' (1996) 3 Alternation 6. See also M Aristodemou 'Studies in law and literature: directions and concerns' (1993) 22 Anglo-American Law Review 160.

$7 \mathrm{~K}$ van Marle \& E Bonthuys 'Feminist Theories and Concepts' in Albertyn, C \& Bonthuys, E (eds) Gender, law and justice (2007) 21. See also S Biko I write what I like: A selection of his writings (1978) 22. 
to what are perceived as 'other' perspectives, which have historically been overlooked or oppressed. 8 This negates the connected nature of all social disciplines and the law itself as a social discipline by focusing only on conventional legal education. ${ }^{9}$

General jurisprudence, in contrast, calls for a critical consciousness to be employed by legal professionals. ${ }^{10}$ This includes the Critical Legal Studies argument that law and legal education should include and utilise the multiple disciplines that the law is part of and relevant to. This includes the multi-disciplinary nature of law itself, with regard to relevant disciplines such as literature, politics and philosophy. ${ }^{11}$ The inclusion of diverse theoretical perspectives is what contributes to a general approach to jurisprudence and, in turn, to transformative legal culture in the Constitutional era. ${ }^{12}$

In educating law students in a post-1994 South Africa, tertiary institutions have the onus to transform higher education. ${ }^{13}$ This, in my view, can only be achieved by a thorough and substantive shift in knowledge production. This substantive shift cannot consist of a mere exposure to different fields of knowledge but should rather entail an engagement with and re-evaluation of 'different' and previously oppressed voices. These voices should furthermore be considered as equal to those of the Eurocentric and mostly male perspectives currently studied. ${ }^{14}$ This substantive shift of knowledge can furthermore be achieved through a trans-disciplinary approach wherein greater focus is awarded to the relationship between 'set' categories of the law that are considered objective, and literature that is considered liberal and subjective. ${ }^{15}$

The imposed classifications of certain knowledge as a commodity in being objective and thus assumed as rational, and other knowledge such as the arts as subjective, and thus inferior in validity, limits legal education to a restricted and formalistic syllabus of only formal legal and economic rules and application. ${ }^{16}$ By acknowledging and furthermore valuing the subjective, liberal and philosophical aspects of typically non-'legal' fields of study such as literature, law students are taught to incorporate different kinds of knowledge for their political philosophy of justice (2005) 3.

9 Waghid (n 2) 458.

10 Douzinas \& Gearey (n 8) 4.

11 A Mbembe 'At the centre of the knot' (2012) 38 Social Dynamics 8.

12 K Klare 'Legal culture and transformative constitutionalism' (1998) 14 South African Journal on Human Rights 150.

13 Waghid (n 2) 457.

14 University of Pretoria, Department of English ENG 110, 120, 210 and 220 study guides (2018).

15 Mbembe (n 11) 8.

16 Mbembe (n 11) 8. 
unique strengths and experiences that can enhance or enrich a law student's application of the law. ${ }^{17}$ By incorporating and interpreting different areas of knowledge in terms of one another, the law student is encouraged to understand humanity and society from as many varying perspectives as possible, so as to ensure an open minded, inclusive and ethically conscious approach to society and its workings in any legal problem. ${ }^{18}$

In promoting a general jurisprudential approach to legal education, English literature promotes, on a base and formal level, better reading, writing skills and analytical skills for law students. ${ }^{19}$ This is of course important for law students, but arguably a smaller aspect of literature's role in legal education when considering the role of literature in teaching and encouraging law students to value the human experience and the position of law in this experience. Maria Aristodemou argues that literature courses in legal education serve more to build ethical and humanistic lawyers that not only work for their society but are also active citizens in it, thus gaining insight into and an understanding of society as a vast and varying structure, and humanness as a value to be sought after in all disciplines. ${ }^{20}$ Literature exposes students to the experiences, history and voices of diverse people who hold different worldviews and addresses the dominant discourse of law to overlook humanistic values. ${ }^{21}$ In legal education this promotes consideration of people's lived experiences as portrayed in literature and prompts the evaluation and understanding of social and political factors that shape different aspects of society and the law.

In being a social concern that permeates all aspects of humanity and society, understanding and valuing the position of the human experience through literature encourages ethical and social sensitivity and empathy in law students. ${ }^{22}$ This is increasingly important in establishing a general approach to legal studies that incorporates diverse views and perspectives, as called for by critical legal studies arguments, to effectively work towards substantive justice. $^{23}$

Such diverse views arise from disciplines such as the humanities, with English literature as a core discipline within the humanities. Literature, and the study of it, teaches law students that humanity is

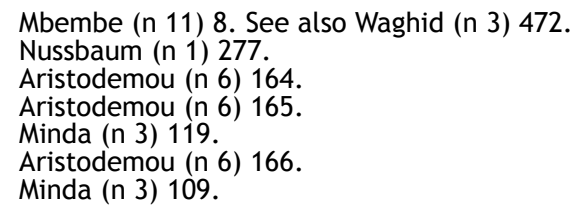


interconnected in varying ways and that the law is one of many components of this interconnectivity. ${ }^{24}$ In exposing law students, as future lawyers, to different and varying perspectives through literature produced by the voices of these perspectives, students broaden their understanding and appreciation of the perceived 'other' as an equally valuable and relevant aspect of the interconnected human experience. ${ }^{25}$ This results in what Martha Nussbaum labels the 'Socratic' lawyer in that they are ethical and open to their approach to and as part of society. ${ }^{26}$ Literature teaches law students to value, understand and empathise with the problems, experiences and voices of others of varying histories. ${ }^{27}$ This is a crucial and invaluable necessity to the pursuit of substantive and meaningful justice in our Constitutional era.

Furthermore, the inclusion of female and African texts in literature studies demonstrates to law students, through analysis, close reading and subjective interpretation, the value of feminine ways of thinking in the legal and literary field. ${ }^{28}$ The consideration of and value awarded to subjective and personal experiences of humanity by law students through the study of literature promotes ethically conscious lawyers that incorporate into their positions as citizens and humans, an understanding of other humans in their approach to the law and pursuit of justice. ${ }^{29}$ Understanding the humanity present in the law by understanding human beings and the rich and diverse different experiences of humanity fosters tolerance, empathy and insight in law students. ${ }^{30}$ This is turn will lead to ethical lawyers who promote further transformation in both society and the legal profession as an inseparable component of society. ${ }^{31}$

\section{Why and how transformation of legal education through a diverse English syllabus is important}

Simply including disciplines such as literature in the legal syllabus does little in terms of transformation in the Constitutional era. The Constitution calls for the 'heal[ing] [of] the divisions of the past' and this healing can only be done through substantive and meaningful change. ${ }^{32}$ Manganyi explains that substantive change can be achieved

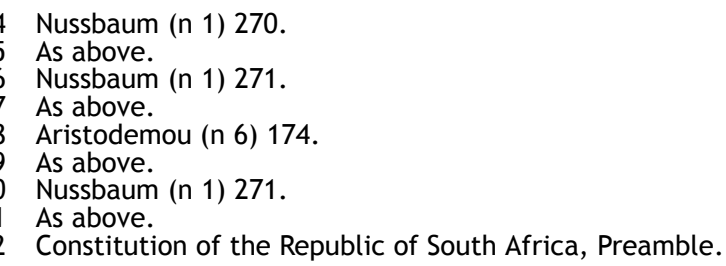


through the interplay between different forces of humanity such as psychology, politics, law and literature. ${ }^{33}$ This interplay also includes the engagement of and interaction with these forces by students on a tertiary level in order to drive socio-political change in legal education and legal culture. ${ }^{34}$

Central to healing and growth is a psychological transformation. Steve Biko explained the notion of a black inferiority complex as the persisting result of systemic and psychological oppression in the pre1994 era that demeans and belittles the experiences and voices of African people to an inferior status than those of European people. ${ }^{35}$ The Black Consciousness Movement (BCM) sought to re-instil pride and self-worth in African people as a means of correcting the psychological oppression of Africans in a pre-1994 era. ${ }^{36}$

The pre-democratic society did not only repress the experience and voices of African people but also those of women. Similar is the effect of cultural and social classifications that stem from the system of patriarchy that is dominant in society, by also denying the value of female perspectives and typically 'feminine' approaches to the law. ${ }^{37}$ Patriarchy structurally influences the upholding and enforcing of male power and domination, as well as male-centred and masculine structures in law. ${ }^{38}$ The so-called 'dichotomies' in legal thinking diminish feminine approaches to education such as, that the perception that the study of humanity and society that arises from the study of literature as part of legal education is inferior to formalistic legal education. ${ }^{39}$ The perception that African people and women and their Afrocentric and feminine ways of thinking and producing knowledge remain inferior or 'less-than' persists even in the modern experiences of these groups. ${ }^{40}$ This oppression and devaluation shape a psychology of dismissal or negation of the possible value and relevance of these approaches to the law and legal education.

When English literature is more diverse and inclusive in exposing students to alternative perspectives that are typically negated, it becomes crucial in transforming the view pertaining to African and female experiences as inferior in value. In exposing law students to these voices and experiences, the process of the BCM's aim of transforming the psychology of African people, and perhaps women too, is continued. This is achieved by offering representation of their

33 N Manganyi 'Public policy and the transformation of education in South Africa' in Sayed, Y \& Jansen, J (eds) Implementing education policies: The South African experience (2001) 28.

34 Manganyi (n 33) 28.

35 Biko (n 7) 22.

36 Biko (n 7) 53.

37 Van Marle \& Bonthuys (n 7) 29.

38 Van Marle \& Bonthuys (n 7) 21.

39 Van Marle \& Bonthuys (n 7) 30.

40 Lindfors (n 6) 6. 
unique lived experiences as portrayed through literature on an equal, non-hierarchical level in value and relevance to Eurocentric and male or 'masculine' voices that shape the perception of humanity for law students. 41

Little or limited transformation of the literature studied, as well as selective and limited inclusion of predominantly male African authors, can be utilised as a dangerous tool to reinforce only dominant voices as superior or relevant. ${ }^{42}$ Pre-1994, only European and predominantly male experiences were considered of any worth and African and female voices were either oppressed or dismissed as unimportant. ${ }^{43}$ In an era of democratic ideals and constitutionally promised equality, no one perspective is dominant if substantive equality is achieved. The substantive transformation of the literature syllabus is imperative to include diverse and previously undervalued voices in the experience of legal education as equal in value and relevance to Eurocentric and male perspectives. This also promotes the practice of equality on a more philosophical level in offering differing and even conflicting perspectives equal status in the study of literature and through this, the study of law as a social profession. ${ }^{44}$ The dangers of not ensuring substantive rather than superficial transformation include creating a disconnection between the Constitutional and transformative gains made in legal culture and the fairly limited and restricted male and European approaches to literature for law students. ${ }^{45}$

Legal education is increasingly transformative in applying feminist and queer theory, critical race theory, and critical legal studies. ${ }^{46} \mathrm{~A}$ formalistic and restricted jurisprudential approach that only values objective, formal rules of law as relevant to legal education can be utilised to enforce the historically oppressive and in-egalitarian relations between deemed 'alternative' knowledge, experiences and perspectives such as those presented to law students in literature. ${ }^{47}$

The onus then shifts to the trans-disciplinary nature of post-1994 legal education for further substantive and overarching transformation. ${ }^{48}$ This trans-disciplinary approach promotes a change in the acquisition of knowledge in legal education, which in turn promotes cooperation between people and ensures a joint responsibility for progress and transformative change as a result of the interconnected and interdependent nature of social fields of

41 Van Marle \& Bonthuys (n 7) 30.

42 Minda (n 3) 113.

43 Minda (n 3) 106.

44 Sec 9 of the Constitution of the Republic of South Africa. See also Aristodemou (n 6) 162.

45 Klare (n 12) 151.

46 Minda (n 3) 109.

47 Minda (n 3) 106.

48 Manganyi (n 33) 28. 
study such as law and literature. ${ }^{49}$ By prescribing both European and African, and male and female texts as equal in status in literature courses, law students are taught to afford equal consideration, value and attention to differing and even contrasting perspectives and to value the enriching dimension of diversity in understanding humanity and working in the legal profession. ${ }^{50}$

This contributes to what Yusef Waghid labels the on-going process of rethinking and redefining the prevalent culture in education. ${ }^{51}$ In response to a democratic era and in incorporating the approach of the Critical Legal Studies scholars in legal education, transformation needs to be an on-going, ever changing journey for the law student into social responsibility and integration of various conflicting or contrasting worldviews and perspectives, so as to better understand and value alternative perspectives to previously dominant ones. ${ }^{52}$ This promotes more direct societal involvement for legal professionals as members of a social profession, which in turn promotes further transformation by producing lawyers who engage in trans-disciplinary legal education to address political and social problems in South Africa, as interactive and engaging components of society. ${ }^{53}$ This also plays a role in promoting ethical legal practice by working with society as fellow humans rather than approaching society from a purely formalistic legal perspective.

Afrocentric transformation features the reframing of European and Western perspectives and experiences through an African lens that is sensitive and aware of African values and experiences. ${ }^{54}$ This is also evident in the call for 'Africanisation' of literary studies. ${ }^{55}$ By studying African and female texts that are authored by African and female authors, African people and women see their experiences reflected in the world around them and also see their experiences as valuable and worthy of acknowledgement. ${ }^{56}$ For law students this illustrates crucial legal and philosophical perspectives that directly impact every aspect of the legal profession and promotes transformation in contributing to the liberation and healing of black and female psychological inferiority complexes. ${ }^{57}$ The psychological liberation of Africans and women through the validation of being valued as crucial to the concept of humanity in legal education, directly promotes transformation in tertiary education. Furthermore,

49 Waghid (n 3) 459.

50 Nussbaum (n 1) 277.

51 Waghid (n 3) 458.

52 As above.

53 Waghid (n 3) 461.

54 P Hugo 'Transformation: The changing context of academia in post-apartheid South Africa' (1998) 97 African Affairs 24.

55 A Mazrui 'Shakespeare in Africa: Between English and Swahili literature' (1996) 27 Research in African Literatures 65.

56 Hugo (n 54) 27.

57 Biko (n 7) 53. 
transformation through valuing multiple and diverse perspectives promotes reconciliation and healing for South Africa and within legal education as a field dominated by Eurocentric and masculine ideals. 58 By acknowledging the value of African and female experiences, an Afrocentric approach may be adopted. This includes approaching literature from all backgrounds from the position of an African vision. ${ }^{59}$ This is crucial in correcting the inferiority present in African psychology by not alienating African perspectives as an 'appendage of the West'.60

\section{If the Western perspective is still relevant}

This prompts a discussion of the role of Western and European perspectives in African legal education. One may argue that an Afrocentric approach to literature studies would negate the need for European texts in the syllabus at all. ${ }^{61}$ However, replacing one dominant perspective with another does not promote transformation and social progression, but rather a continued cycle of one aspect of the human experience being deemed superior at the expense of another. Western English literature has a deep history and is relevant to many human experiences. ${ }^{62}$ Approaching European literature from an Afrocentric perspective may promote additional transformation of legal education in teaching law students to accommodate external or Western perspectives in the Constitutional era's specific focus on equality, diversity and transformative progress. ${ }^{63}$ This also teaches law students to incorporate various worldviews and experiences in a manner that ensures that no one perspective is valued as dominant and that multiple human experiences can be valued without encroaching on or being thwarted by another. ${ }^{64}$ Such a co-operation of perspectives fosters an approach to law and society that features joint and mutual responsibility for transformative change between law students and lawyers, and the society they interact with. ${ }^{65}$

58 Klare (n 12) 68.

59 Hugo (n 54) 26.

60 Hugo (n 54) 26 and Biko (n 7) 22.

61 Mazrui (n 55) 64.

62 Mazrui (n 55) 76.

63 Mazrui (n 55) 65.

64 Biko (n 7) 22.

65 Waghid (n 2) 471. 


\section{How the current English syllabus has become more inclusive but fails to meet expectations of transformation}

After 1994, an effort was made to reform and reorganise the texts being studied in South African universities to be more inclusive and representative of South Africa. ${ }^{66}$ This included both introducing texts about African and female experiences and texts written by African and female authors. ${ }^{67}$

Both LLB and BA Law students typically complete the modules ENG 110 and 120 and BA Law students go further to also complete ENG 210 and 220. ENG 110 covers 'pre-twentieth century era' texts, ENG 120 covers ' post-nineteenth century' literature, ENG 210 covers 'Modern English literature and English language studies' and ENG 220 'Twentieth-century and postcolonial' literature. ${ }^{68}$

The introduction of more African and female texts is evident in the prescribed texts for 2018 English literature courses for law students at the University of Pretoria. ${ }^{69}$ However, the unequal divide between texts authored by white males and black males, as well as males overall and females overall is strikingly apparent. Excluding selected poets in a South African poetry section of the 120 module, ENG 110 and 120 collectively feature seven white male writers of novels and plays (of which two are South African namely Medalie as contributor and Fugard) and one black male writer, Achebe. ${ }^{70}$ Only one female author of novels and plays is studied in ENG 110 and 120 and that is Dangarembga with her award-winning novel 'Nervous Conditions'. ${ }^{71}$ The value awarded to European knowledge as superior is still evident in the ratio of white South African authors being included as African voices, as compared to the one black and Nigerian novelist voicing black African experiences. Other literature in the course classified as 'African literature' is Conrad's 'Heart of Darkness'. While being set in Africa and regarding African history, the text is arguably not transformative in nature in being included on the syllabus as it reinforces the Eurocentric evaluation of relevance in valuing Conrad's Western portrayal of an African experience as an African perspective. ${ }^{72}$

Lindfors (n 6) 6.

As above.

University of Pretoria, Department of English ENG 110, 120, 210 and 220 study guides (2018).

As above.

As above.

As above.

Lindfors (n 6) 13. 
Little difference is seen in ENG 210 and 220 which collectively feature eight novels and plays by white males (of which one author is South African, JM Coetzee) and two by black males (of which neither are South Africa but one author is African, Ngũgĩ wa Thiong'o). ${ }^{73}$ There is also a prominent racial divide between female authors of prose and drama, where in ENG 210, 'Modernism and Language Studies', there are two female European writers and in ENG 220's 'Twentieth-century and postcolonial literature', there are two female African writers. ${ }^{74}$ The ENG 220 module does, however, also include additional nonEuropean texts such as Caribbean and South African poetry and Asiancentric texts by authors such as Hamid and Kureishi, as well as female author Julie Otsuka. ${ }^{75}$ However, the prominent bias that still exists in the syllabus towards European male authors such as Yeats, Joyce and Miller highlights the unequal weighing of value awarded to these authors in favour of female and African authors such as Omotoso and Adichie. ${ }^{76}$ Despite this, the diverse perspectives included in the ENG 220 module arguably make it the most transformative of the English literature modules in presenting non-European views and both male and female voices as valuable and representative of society. This is problematic when considering that the LLB program typically does not include ENG 220. LLB students are then only presented with two black writers, four African writers in total and only one female writer. ${ }^{77}$ For the BA Law student, the inclusion of ENG 220 in the program promotes consideration of diverse perspectives as well as a truly general jurisprudential approach in comparatively and substantively pursuing legal education from a truly trans-disciplinary approach. ${ }^{78}$

While the English syllabus has changed a great deal from pre-1994 trends, the transformation achieved through studying African and female texts in the syllabus lacks the substantive change needed to be truly transformative for law students, more so in a post-1994 era. ${ }^{79}$ The efforts of South African universities and specifically the University of Pretoria to reform the literature syllabus are limited and slow, but nonetheless, progressing. ${ }^{80}$ The inclusion - albeit limited inclusion - of African classics such as Achebe's 'Things fall apart' and Ngũgĩ's 'A grain of wheat' gives recognition to African voices, but are often included in only one literature course for law students (such as only ENG 120 for LLB students) and, while voicing African experiences, these African classics still expose law students to a male

73 University of Pretoria, Department of English ENG 110, 120, 210 and 220 study guides (2018).

74 As above.

75 As above.

76 Lindfors (n 6) 7.

77 University of Pretoria, Department of English ENG 110, 120, 210 and 220 study guides (2018).

78 Nussbaum (n 1) 272.

79 Klare (n 12) 151.

80 Lindfors (n 6) 6. 
dominated experience that reinforces the dominance of 'masculine' approaches to society being the preferred approach to law. ${ }^{81}$

The position of female African writers in English literature courses throughout South African universities is exceptionally limited to Dangarembga's 'Nervous conditions' and various novels by Gordimer, with few variations in texts between universities being studied. ${ }^{82}$ The divide between value and prominence awarded to male and specifically white male texts and African female and female texts is evident in the persisting preference for masculine approaches to legal education. ${ }^{83}$ The value placed on objectivity, rationality, analytical skills and impartiality illustrate the value of masculine traits over more subjective, contextual and emotive feminine approaches to law and legal studies. 84

\section{Conclusion}

In promoting transformation of legal education in post-1994 South Africa, law students are increasingly being trained from a transdisciplinary approach in that the study of literature forms part of the syllabus, albeit with slow transformative progress. This is in an effort to employ a general approach to jurisprudence and a Critical Legal studies perspective by including studies of the humanities in the study of law and acknowledging the role of disciplines such as literature in creating citizens of lawyers. ${ }^{85}$ The exposure of LLB students to literature in the law syllabus should aim to expose law students to varying and diverse experiences of different groups of society as portrayed in African and female literature. ${ }^{86}$

By presenting law students with predominantly Eurocentric and male texts in literature courses, transformative efforts of tertiary institutions lack significant or meaningful change. ${ }^{87}$ Mere inclusion of literature in legal education is limited in transformative potential as studying only one experience can be used to enforce dominant perspectives as superior and solely worthy of recognition. ${ }^{88}$ By including more diverse and even Afrocentric voices such as African and female writers in the English syllabus, law students are presented with more varied and more relatable texts in an African context that promotes understanding and sensitive consideration of previously

Lindfors (n 6) 8.

Lindfors (n 6) 7

Van Marle \& Bonthuys (n 7) 29.

As above.

Nussbaum (n 1) 271.

Nussbaum (n 1) 270.

Manganyi (n 34) 28.

88 Aristodemou (n 6) 177. 
marginalised voices and undervalued perspectives portrayed in literature. 89

The inclusion and appreciation of such perspectives is instrumental in correcting and addressing the psychological oppression of women and Africans following years of - and sometimes still persisting - systematic oppression in structures such as the patriarchy and the black inferiority complex. ${ }^{90}$

Furthermore, the role of English literature in legal education is also in declassifying the strict and formal categories of knowledge considered appropriate and relevant to legal studies, and incorporating and integrating typically liberal and subjective disciplines, such as literature and the arts, in a general jurisprudential approach to legal education in post-1994 South Africa. ${ }^{91}$ Such approaches are typically deemed 'feminine' and thus contribute to a Critical Legal studies approach to legal education in incorporating the value of feminine and other undervalued theoretical approaches to legal education. ${ }^{92}$

In creating ethical law students and later, ethical lawyers, English literature that is transformative in itself by incorporating diverse experiences in an equal, non-hierarchical manner, can promote an understanding and consideration for 'other' perspectives. ${ }^{93}$ This promotes an ethical consciousness in lawyers and is highlighted by the social nature of the legal discipline. ${ }^{94}$ Law is an integral part of humanity, and humanity an integral part of law. ${ }^{95}$

While literature courses feature some progression and development, there has been fairly limited transformation in ENG modules to include diverse and perceived 'alternate' perspectives such as female and African voices in studied texts. ${ }^{96}$ White male authors make up a large majority of the texts being studied by law students in literature courses which exhibits limited and superficial transformative measures. ${ }^{97}$ In striving for substantive transformation, including trans-disciplinary and diverse experiences and perspectives creates a legal consciousness that further plays a role in training ethical lawyers that will promote further transformation of society and legal education in their careers. ${ }^{98}$ 
Incorporating diverse and representative texts in literature courses for law students promotes a general jurisprudential approach to legal education in including the humanities in an inherently social field of study. ${ }^{99}$ This ensures substantive justice and an approach to law that values previously dismissed or devalued perspectives such as those of females, Africans and subjective, feminine and transdisciplinary approaches to legal education in post-1994 South Africa.

99 Nussbaum (n 1) 271. 